\title{
Managing mood disorders in patients attending pulmonary rehabilitation clinics
}

This article was published in the following Dove Press journal:

International Journal of COPD

3 January 2013

Number of times this article has been viewed

\section{Colleen Doyle ${ }^{1-3}$ \\ David Dunt ${ }^{2}$ \\ David Ames' \\ Suganya Selvarajah'}

'National Ageing Research Institute, Royal Melbourne Hospital Royal Park Campus, Parkville, Victoria, Australia; ${ }^{2}$ Centre for Health Policy, Programs and Economics, University of Melbourne, Parkville, Victoria, Australia; ${ }^{3}$ Australian Catholic University, Fitzroy, Victoria, Australia
Correspondence: Colleen Doyle National Ageing Research Institute, PO Box 2I27, Royal Melbourne Hospital, Parkville 3050, Victoria, Australia

Tel +6I 383872305

Fax +6I 398374030

Email c.doyle@nari.unimelb.edu.au
Background: There is good evidence for the positive benefits of pulmonary rehabilitation (PR) in the prevention of hospital admissions, lower mortality, and improved health-related quality of life. There is also increasing evidence about the impact of PR on mental health and, in particular, mood disorders. We aimed to identify how depression in chronic obstructive pulmonary disease (COPD) patients in Victoria, Australia, is being managed in PR, to identify the prevalence of depressive symptoms among COPD patients who attend PR, and to determine whether patients with depressive symptoms or anxiety symptoms dropped out of PR early.

Method: Of 61 PR clinics, 44 were invited and 22 agreed to participate. Telephone interviews were conducted to see how depression and anxiety in COPD patients were being recognized and managed in these clinics. A total of 294 questionnaires were distributed to patients by clinic coordinators to determine the prevalence of anxiety/depression, as measured by the Hospital Anxiety and Depression Scale. Coordinators were contacted to provide information on whether respondents dropped out of rehabilitation early or continued with their treatment at 2-4 months post program.

Results: Seven clinics were not aware of local guidelines on assessment/treatment/management of mood. Four clinics did not use any screening tools or other aids in the recognition and management of depression and/or anxiety. Overall, eight clinics participating in this study requested advice on suitable screening tools. The patient survey indicated that the mean depression score on the Hospital Anxiety and Depression Scale was 5.0 (standard deviation 3.0, range 1-13). The mean anxiety score was 5.5 (standard deviation 3.4, range $0-18$ ). There was no evidence of a link between failure to complete rehabilitation and depression or anxiety scores, as only three of 105 patients failed to complete their rehabilitation.

Discussion: Awareness of management guidelines for depression and anxiety in COPD patients was variable across the clinics recruited into our study. We found no link between compliance with rehabilitation and depression, but our sample had limitations.

Conclusion: Future research needs to investigate how best to encourage more use of available guidelines regarding integrating psychological and psychosocial support to supplement the exercise and education that are currently offered routinely by all PR clinics studied in Victoria, Australia.

Keywords: chronic obstructive pulmonary disease, depression, anxiety, pulmonary rehabilitation

\section{Background}

The importance of pulmonary rehabilitation (PR) in the management of chronic obstructive pulmonary disease (COPD) is now well recognized. ${ }^{1}$ There is good evidence for the positive benefits of PR in the prevention of hospital admissions, lower mortality, and 
improved health-related quality of life. ${ }^{1}$ There is also increasing evidence for a positive impact of PR on mood disorders such as depression and anxiety, which are common comorbidities of COPD. ${ }^{2}$ The published prevalence rates for depression in COPD patients vary widely, ${ }^{3-9}$ but some estimates of depression in COPD patients are around $50 \%{ }^{10}$ or, for severe COPD, approximately 2.5 times greater than in an age-matched control population, ${ }^{11}$ and significant depression symptoms have been reported in $16 \%-74 \%$ of patients with COPD. ${ }^{4,9,12-14}$ Studies employing the Hospital Anxiety and Depression Scale (HADS) found estimates of prevalence ranging from $2 \%$ to $47 \%{ }^{4-8,15,16}$ Undiagnosed and untreated depression in patients with COPD is associated with noncompliance with medical treatment and reduced quality of life. ${ }^{17}$ Compared with nondepressed patients, the odds are three times greater that depressed patients will be noncompliant with medical treatment recommendations. ${ }^{17}$ Nevertheless, in Australia, mental disorder comorbidity has been grossly under-recognized in patients with COPD. ${ }^{18}$

Internationally, there are well-established clinical guidelines for the treatment of depression and anxiety associated with COPD in the United Kingdom. ${ }^{19}$ According to the British guidelines, the presence of anxiety and depression should be considered in patients who are hypoxic $\left(\mathrm{SaO}_{2}\right.$ less than 92\%), who have severe dyspnea, and who have been seen at, or admitted to, a hospital with an exacerbation of COPD. The guidance recommends that patients found to be depressed or anxious be treated with conventional pharmacotherapy, and, for those undergoing antidepressant treatment, that time is spent with the patient explaining why depression needs to be treated. Optimal care for COPD patients may require combining pharmacologic with nonpharmacologic therapies. Pharmacologic treatment of depression in COPD patients may be less tolerated than nonpharmacologic treatments, due to side effects such as sedation, which may cause respiratory depression and aggravate sleep disturbances. ${ }^{20}$ Nonpharmacologic therapies include smoking cessation and encouragement of physical activity, education, collaborating on self-management plans, and cognitive behavior therapy., ${ }^{2,21}$ In Australia we have COPD guidelines that are a joint publication from the Australian Lung Foundation and the Thoracic Society of Australia and New Zealand. ${ }^{20,22}$ The Australian guidelines summarize international evidence for pharmacologic treatments but also summarize the evidence for treatments for anxiety and depression. The guidelines include recommendations for referrals to psychologists and psychological supports, the use of patient support groups for psychosocial supports, and screening for anxiety and depression symptoms using standardized screening scales such as the HADS. ${ }^{22}$

\section{Rationale}

This project focused on what systems are available for the recognition of depression and anxiety at Victorian PR clinics. We aimed to identify how depression and anxiety in COPD patients are being managed in PR, awareness of management guidelines, and the prevalence of depressive symptoms among COPD patients who attend PR in Victoria. Although the relationship between anxiety, depression, and adherence to PR has been examined elsewhere (Harrison et $\mathrm{al}^{2}$ ), there have been no studies of the impact of anxiety and depression on adherence to PR as it is practised in Victoria or on the relationship between awareness of COPD management guidelines and mood disorders in PR patients. Specifically, we asked the following research questions:

1. How are depression and anxiety in COPD patients recognized and managed in PR clinics in Victoria?

2. What is the prevalence of depression/anxiety among a sample of people attending PR clinics in Victoria?

3. Do people who drop out of PR as it is practised in Victoria, Australia, have higher anxiety or depression scores as measured by the HADS than people who complete their course of rehabilitation?

\section{Methodology}

We conducted a large, cross-sectional, multicenter study in the state of Victoria, Australia, to address the aforementioned research questions. To answer research question (1), qualitative telephone interviews were conducted with PR coordinators to explain programs offered, management of depression/anxiety, and awareness of local treatment guidelines of COPD-X ${ }^{19}$ and local hospital admission prevention guidelines (Hospital Admission Risk Program guidelines). Clinic coordinators were invited to participate in the study via email and telephone or face-to-face follow-up. Of 61 clinics in the state of Victoria, 44 were invited and 22 agreed to participate in the study (50\% response rate). Clinics whose ethics procedures were too expensive or outside the time frame of the study were not included in the study. The telephone interview covered the following topics: reach of the program (number of patients), components of the program, use of depression and anxiety guidelines, screening tools used, and referral pathways.

To answer research question (2), a total of 294 questionnaires were distributed to patients of the 22 PR clinics by clinic coordinators. This was a purposive sample (a nonrandom sample selected for a specific purpose) of people (both male and female aged 18 years of age and above) attending PR following a diagnosis of COPD in Victorian PR clinics, within a specified time frame, which depended on the length of program cycle run 
at each clinic. We were not able to select a random sample of all patients attending each clinic, because of limitations of time and funding. Inclusion criteria were: diagnosis of COPD, over 18 years of age, and assessed as eligible to attend PR. Because we were engaging third-party recruitment, ie, coordinators distributed questionnaires on behalf of the research team, and because the number of patients attending PR during the survey period varied, the number of questionnaires distributed to each site varied from six to 25 per clinic. A total of 105 completed questionnaires were returned, with the response rate of questionnaires received from the 22 clinics ranging from $0 \%$ to $90 \%$, and an overall response rate of $36 \%$ achieved with third-party recruitment of patients.

The self-report questionnaire for patients covered the following domains: social well-being (age, sex, marital status, living arrangements, social supports), physical well-being (COPD history, severity [self-reported, single item indicating mild, moderate, or severe], smoking history, exercise), psychological well-being (the HADS and Duke Social Support Index ${ }^{23}$ [social interaction component]), and service use (PR clinic attendance). The HADS is not a clinical diagnostic tool, but it does identify symptoms of anxiety and depression and is used to grade severity of symptoms using a well-established cutoff point. ${ }^{24,25}$ Responses on the HADS questionnaire are ordinal, ranging from 0 to 3 for each item and 0 to 21 for each subscale score. The HADS subscale scores for anxiety and depression were calculated by summing the scores for each of seven questions, giving a total possible score of 21 for each subscale. On the HADS, a low score for both subscales of depression and anxiety is considered to be less than 7, whereas scores of between 8 and 10 are suggestive of case-level disorder, and a score over 11 indicates significant disorder. ${ }^{25}$ The scale can be administered by a health professional or completed as a self-report questionnaire by the patient. ${ }^{24}$

To answer research question (3), coordinators were contacted by the research team to provide information on whether respondents dropped out of rehabilitation early or continued with their treatment to the satisfaction of their health professional at $2-4$ months post program. This information was then compared with patients' depression and anxiety scores.

\section{Results}

\section{Description of the PR programs}

Most programs ran as stand-alone services belonging to a larger health organization. All clinics had a multidisciplinary team attending to the patients at various stages throughout the program. However, the physiotherapist and allied health staff were mainly responsible for onsite running of the program. Although the overall rehabilitation program resulted from multidisciplinary contributions, the physiotherapist usually worked alone in providing the exercise component. The numbers of patients attending each program varied from five to 15 (average $\mathrm{n}=8$ ), depending on client compliance and attendance since initial assessment to enter the program. Most ( $n=12$ ) PR programs were run on an ongoing (continuous) basis, whereas six clinics ran intermittent programs (one to four programs per year). Program sessions varied from once weekly for 8-12 weeks to twice weekly for 6-10 weeks.

On average, patients attended twelve program sessions based on a twice-weekly, 6-week program cycle.

\section{Components of the programs}

All programs $(100 \%, \mathrm{n}=22)$ included an exercise component and an education component, and most, but not all, clinics included psychosocial or psychological support to varying degrees.

Table 1 shows the amount of psychological and psychosocial support offered in the clinics. Over onethird of clinics $(36 \%)$ did not offer any psychological support to patients. The remainder, $23 \%(\mathrm{n}=5)$ offered formal psychological support from specialist staff, and the majority (63\%) offered informal psychological support.

Ten clinics referred their patients to patient support groups, and eight clinics had no links to any patient support groups. Although there was a general preference by coordinators to establish support groups, factors such as varied literacy levels of patients, diverse ethnicities, and poor patient compliance acted as barriers hindering this type of support being available.

\section{Use of depression and anxiety guidelines/ screening tools/referral pathways}

When clinic coordinators were asked about guidelines for management of mood in their patients, $32 \%$ (seven of 22 )

Table I Types of psychological support offered in a sample of pulmonary rehabilitation clinics (categories are not mutually exclusive)

\begin{tabular}{ll}
\hline Type of psychological support & $\begin{array}{l}\text { Percentage of clinics } \\
(\mathbf{n}=\mathbf{2 2})\end{array}$ \\
\hline $\begin{array}{l}\text { Formal } \\
\text { Informal }\end{array}$ & $23 \%(n=5)$ \\
$\quad$ Psycho-education & $14 \%(n=3)$ \\
Social worker/counselor & $27 \%(n=6)$ \\
Support group & $9 \%(n=2)$ \\
Debrief only & $4 \%(n=I)$ \\
None & $36 \%(n=8)$ \\
\hline
\end{tabular}


were not aware of COPD-X guidelines on assessment, treatment, or management of mood disorders. The majority of coordinators, however, were aware of these guidelines and found them to be either useful or very useful in terms of applicability to the rehabilitation program. Twenty-three percent of coordinators found the guidelines to be very useful in forming the framework/structure of the rehabilitation program and how the rehabilitation program operates broadly. One coordinator, in particular, stated that the recent update of these guidelines prompted a revision of the clinic's pulmonary rehabilitation program, and another stated that these guidelines were used in annual reviews. A third coordinator stated that the Hospital Admission Risk Program and COPD-X guidelines ensured uniformity and similarity in approach. In addition to these guidelines, one rehabilitation clinic also referred to US Pulmonary Best Practice guidelines, although none referred to the UK guidelines.

Despite a substantial proportion of clinics not providing formal psychological support for their patients, most used screening tools or broader psychosocial tools to measure quality of life, which to some extent contained emotional or psychological indicators of well-being. All except four clinics used some specific mood disorder tool, a broader tool, or informal methods to screen for depression and anxiety amongst their patients. Tools used included the Chronic Respiratory Disease Questionnaire, Quality of Life Questionnaire, RAND-36 Health-related Quality of Life Survey, Short Form-36 Health Survey, GUYATT Quality of Life Tool, St George's Respiratory Questionnaire and Depression Anxiety Stress Scales, and the HADS. Overall, depression and anxiety screening tools were considered useful at all clinics participating in this study, with requests for recommendation of suitable screening tools, but many clinics did not use tools that were specifically measuring depression and anxiety. Some of the issues raised in relation to screening tools included that the HADS was not particularly useful, due to it being nonspecific to respiratory diseases.

When questioned about what paths were used to refer patients with depressive symptoms if they were recognized, most clinics used either formal or informal referral paths and processes to manage patients with depressive symptoms.

These referral paths included referral to community health services (eg, counselor, social worker, dietician, client's general practitioner, etc) or to the counselor or psychologist within the organization, and providing information regarding services such as beyondblue (a community organization specialising in anxiety and depression). In instances where the client had a mental health care plan, this was taken into account in responding to a perceived need to refer, and this referral was likely to be to the primary care physician. Often, clinics used a care assessment tool that identifies referral pathways for risk factors when the client is initially assessed to enter a rehabilitation program. In some clinics, all health professionals in the multidisciplinary rehabilitation team, including the client's referring doctor, were involved in the referral process to a psychologist. Referrals to psychological care and support were made through the social worker or welfare or other health network structures. Usually, the respiratory physician or the counselor was involved in referring, with contribution, although to a lesser extent, from the client's primary care physician.

Three clinics followed informal referral mechanisms when psychological concerns in patients were identified. This was due to inadequate program (organizational) structure and lack of means (ie, lack of training to identify and deal with patients exhibiting mood disorders, lack of referral processes to implement, lack of assessment/screening tools) to manage patients with depressive symptoms. Two of these clinics were able to identify patients with depressive symptoms through this study, which enabled the patients to be referred on for further support.

However, again, 32\% $(n=7)$ of clinics did not have a process for managing depression. Reasons for not using any referral pathways included lack of an onsite psychologist and no responsibility for cases where the patient already had a doctor managing their mental health.

In summary, although the majority of clinics surveyed had some awareness of local guidelines to manage anxiety and depression associated with COPD, approximately one-third of clinics lacked formal mechanisms for detecting mood disorders, adequate staffing to manage symptoms, or adequate referral pathways.

\section{Patient sample results}

In this context we attempted to determine the prevalence of anxiety and depression symptoms in patients from the sample of PR clinics. We received questionnaires from 105 patients, and all questionnaires were completed fully. We found that of the sample of 105 patients surveyed in these 22 clinics, $43 \%$ were male and 57\% were female. The mean age was 70.9 years (standard deviation [SD] 8.3 years, range 52-90 years). Approximately one-third (31\%) lived alone. The mean Duke Social Support Index score was 8.0 (SD 1.6). When patients were asked to self-rate their COPD symptoms, $20.2 \%$ rated them as mild, $67.7 \%$ 
rated them as moderate, and $12.1 \%$ rated them as severe. Therefore, the majority of these patients were experiencing moderate to severe COPD symptoms. Most patients (71.6\%) were previous smokers. In this sample, the mean depression score from the HADS was 5.0 (SD 3.0, range 0-13) and the mean anxiety score was 5.5 (SD 3.4, range $0-18$ ). Therefore, the mean depression and anxiety scores were within the normal range. However, the range of scores indicated that a number of patients were experiencing concerning symptoms of depression and/or anxiety. When we analyzed scores that were suggestive of case-level depression, we found that, overall, $20.4 \%$ of patients reported depression and $27.2 \%$ of patients reported suggestive or case-level anxiety. However, these patients were not clustered within clinics that had no formal psychological supports.

Correlating social network scores with depression and anxiety, there was a negative, but nonsignificant, correlation, ie, people with lower social network scores tended to have higher depression scores, although the relationship was not significant. In addition, there was no evidence of a link between depression or anxiety symptom scores and compliance with programs. We found only three patients of the 105 surveyed who did not complete the program of PR (one client with high depression/anxiety, two without). Therefore, there were insufficient numbers to calculate any statistical relationship between completion of PR and the HADS subscale scores.

\section{Discussion}

Although awareness is growing of the importance of being aware of mood disorders and their impact on COPD, we found that there is still some way to go in integrating psychological and psychosocial support into PR programs in Victoria, Australia. Awareness of management guidelines for depression and anxiety in COPD patients was variable across the clinics recruited into our study. Although some clinics were well connected into psychological and psychosocial supports for the region, other clinics had very limited access to psychological support for their patients and no links to patient support groups. Our study showed that although PR clinics pay some attention to the psychological well-being of patients, there was only moderate use and awareness of current guidelines for management of depression and anxiety. Results of the client survey indicated that although the overall mean depression and anxiety scores were within the normal range, there were a fair proportion of patients with suggestive or case-level disorder. However, it was not related to compliance with the course of rehabilitation.
Study results of the prevalence of depression in hospital samples have been very variable. The prevalence found in the present study was in the middle of the range of previous prevalence studies. ${ }^{4,9,10,26}$

The main goals of COPD management are to lessen airflow limitation, prevent and decrease symptoms, prevent and treat medical complications, and improve daily living and quality of life. ${ }^{22}$ Mood disorders can have a direct effect on the likelihood of meeting these goals, and depression has been associated with poorer outcomes in patients with COPD. ${ }^{14}$ Unlike previous studies, we found no link between compliance with rehabilitation and depression. However, our respondents may have been the most motivated ones to maintain their program among PR patients. In light of limited rehabilitation resources, patients for rehabilitation are carefully selected to ensure that they can cope with the program, so patients with higher levels of depression or anxiety may avoid rehabilitation or be referred elsewhere, and patients with higher depression or anxiety who were accepted into rehabilitation may have been less likely to participate in our survey. The limitations of the study were that the 22 clinics that responded to the invitation to participate may not have been representative of the other clinics in the state. The range of clinics covered large government-funded sites as well as smaller community sites and rural, regional, and urban settings. The small sample of patients surveyed may not have been representative of all patients attending PR. Self-rated COPD severity was not externally validated with standardized measures such as forced expiratory volume in 1 second or forced expiratory volume/forced vital capacity. Finally, we were not able to determine whether patients with case-level anxiety or depression had any previous or current pharmacologic or nonpharmacologic treatments, as these data were not collected for individuals.

\section{Conclusion}

Given the importance of providing psychological and psychosocial support for COPD patients in order to maximize the effect of rehabilitation on quality of life, ${ }^{23}$ future research needs to investigate alternative models of support to supplement the exercise and education that are currently offered routinely by all PR clinics studied here. Some studies have reported that cognitive behavior therapy can be helpful for COPD patients. ${ }^{2}$ Future research is needed to investigate efficient ways to provide psychological and psychosocial support as part of PR, as well as at other stages in the pathway of management of the disease. 


\section{Acknowledgment}

This research project was funded by beyondblue Research Grant 08DOY1. beyondblue: the national depression initiative. Details of human research ethics approvals obtained for the study are available on request.

\section{Disclosure}

The authors report no conflicts of interest in this work.

\section{References}

1. Puhan MA, Gimeno-Santos E, Scharplatz M, Troosters T, Walters EH, Steurer J. Pulmonary rehabilitation following exacerbations of chronic obstructive pulmonary disease. Cochrane Database Syst Rev. 2011;(10): Art No: CD005305. DOI: 10.1002/14651858.CD005305.pub3.

2. Harrison SL, Greening NJ, Williams JE, Morgan MD, Steiner MC, Singh SJ. Have we underestimated the efficacy of pulmonary rehabilitation in improving mood? Respir Med. 2012;106(6):838-844.

3. McSweeny AJ, Grant I, Heaton RK, Adams KM, Timms RM. Life quality of patients with chronic obstructive pulmonary disease. Arch Intern Med. 1982;142:473-478.

4. Light RW, Merill EJ, Despars JA, Gordon GH, Mutalipassi LR. Prevalence of depression and anxiety in patients with COPD. Chest. 1985;87(1):35-38.

5. Jones PW, Baveystock CM, Littlejohns P. Relationship between general health measured with the Sickness Impact Profile and respiratory symptoms, physiological measures and mood in patients with chronic airflow limitation. Am Rev Respir Dis. 1989;140(6):1538-1543.

6. Bosley CMC, Corden ZM, Rees PJ, Cochrane GM. Psychological factors associated with the use of home nebulized therapy for COPD. Eur Respir J. 1996;9:2346-2350.

7. Engstrom CP, Persson LO, Larsson S, Ryden A, Sullivan M. Functional status and well-being in chronic obstructive pulmonary disease with regard to clinical parameters and smoking: a descriptive and comparative study. Thorax. 1996;51(8):825-830.

8. White RJ, Rudkin ST, Ashley J, Stevens VA, Burrows S, Punsford JC, et al. Outpatient pulmonary rehabilitation in severe chronic obstructive pulmonary disease. J R Coll Physicians Lond. 1997;31(5):541-545.

9. Yohannes AM, Baldwin RC, Connolly MJ. Depression and anxiety in elderly outpatients with chronic obstructive pulmonary disease; prevalence and validation of the BASDEC screening questionnaire. Int J Geriatri Psychiatry. 2000;15(12):1090-1096.

10. Mikkelsen RL, Middleboe T, Pisinger C, Stage K. Anxiety and depression in patients with chronic obstructive pulmonary disease (COPD). A review. Nordic J Psychiatry. 2004;58(1):65-70.

11. Van Manen JG, Bindels PJ, Dekker FW, Ijzermans CJ, van der Zee JS, Schadé E. Risk of depression in patients with chronic obstructive pulmonary disease and its determinants. Thorax. 2002;57(5):412-416.
12. Yellowlees PM, Alpers JH, Bowden JJ, Bryant GD, Ruffin RE. Psychiatric morbidity in patients with chronic airflow obstruction. Med J Aust. 1987;146(6):305-307.

13. Karajgi B, Rifkin A, Doddi S, Kolli R. The prevalence of anxiety disorders in patients with chronic obstructive pulmonary disease. Am J Psychiatry. 1990;147(2):200-201.

14. Ng TP, Mathew N, Tan WC, Cao Z, Ong KC, Eng P. Depressive symptoms and chronic obstructive pulmonary disease. Arch Intern Med. 2007;167(1):60-67.

15. Stage KB, Middleboe T, Pisinger C. Measurement of depression in patients with chronic obstructive pulmonary disease (COPD). Nordic J Psychiatry. 2003;57:297-301.

16. Stage KB, Middelboe T, Pisinger C. Depression and chronic obstructive pulmonary disease (COPD). Impact on survival. Acta Psychiatr Scand. 2005;111:320-323.

17. DiMatteo MR, Lepper HS, Croghan TW. Depression is a risk factor for noncompliance with medical treatment; meta-analysis of the effects of anxiety and depression on patient adherence. Arch Intern Med. 2000;160(14):2101-2107.

18. Frith PA, Cafarella PA, Duffy JM. Chronic obstructive pulmonary disease (COPD) is a major personal and public health burden in Australia. Aust N Z J Public Health. 2008;32(2):139-141.

19. National Institute for Health and Clinical Excellence. Chronic obstructive pulmonary disease. Management of chronic obstructive pulmonary disease in adults in primary and secondary care. CG101. London, UK: National Institute for Health and Clinical Excellence; 2004.

20. McKenzie DK, Frith PA. The COPDX Plan: Australian and New Zealand guidelines for the management of chronic obstructive pulmonary disease. Med J Aust. 2003;178(6):1-39.

21. ZuWallack R. The nonpharmacologic treatment of chronic obstructive pulmonary disease. Advances in our understanding of pulmonary rehabilitation. Proc Am Thorac Soc. 2007;4(7):549-553.

22. McKenzie DK, Abramson M, Crockett AJ, Dabscheck E, Glasgow N, Jenkins S, et al; on behalf of the Australian Lung Foundation. The COPD-X Plan: Australian and New Zealand guidelines for the management of chronic obstructive pulmonary disease V2.30; 2011.

23. Lauderman RL, George LK, Campbell RT, Blazer D. Alternative models of the stress buffering hypothesis. Am J Community Psychol. 1989;17(5):625-642.

24. Zigmond AS, Snaith RP. The Hospital Anxiety and Depression Scale. Acta Psychiatrica Scandinavica. 1983;67(6):361-370.

25. Bjelland I, Dahl AA, Haug TT, Neckelmann D. The validity of the HADS: an updated literature review. J Psychosom Res. 2002; 52(2):69-77.

26. Coventry PA, Gellatly JL. Improving outcomes for COPD patients with mild-to-moderate anxiety and depression: a systematic review of cognitive behavioral therapy. Br J Health Psychol. 2008;13(3):381-400.

27. Garcia-Aymerich J, Barreiro E, Farrero E, Marrades RM, Morera J, Anto JM. Patients hospitalized for COPD have a high prevalence of modifiable risk factors for exacerbation (EFRAM study). Eur Respir J. 2000;16(6):1037-1042.
International Journal of COPD

\section{Publish your work in this journal}

The International Journal of COPD is an international, peer-reviewed journal of therapeutics and pharmacology focusing on concise rapid reporting of clinical studies and reviews in COPD. Special focus is given to the pathophysiological processes underlying the disease, intervention programs, patient focused education, and self management protocols.

\section{Dovepress}

This journal is indexed on PubMed Central, MedLine and CAS. The manuscript management system is completely online and includes a very quick and fair peer-review system, which is all easy to use. Visit $\mathrm{http}: / / \mathrm{www}$.dovepress.com/testimonials.php to read real quotes from published authors. 